\title{
Evaluation of subsidence, chondrocyte survival and graft incorporation following autologous osteochondral transplantation
}

\author{
Niels B. Kock • Gerjon Hannink • Albert van Kampen • \\ Nico Verdonschot · Job L. C. van Susante • \\ Pieter Buma
}

Received: 22 December 2010/Accepted: 2 May 2011/Published online: 9 September 2011

(C) The Author(s) 2011. This article is published with open access at Springerlink.com

\begin{abstract}
Purpose The aim of this study was to evaluate subsidence tendency, surface congruency, chondrocyte survival and plug incorporation after osteochondral transplantation in an animal model. The potential benefit of precise seating of the transplanted osteochondral plug on the recipient subchondral host bone ('bottoming') on these parameters was assessed in particular.

Methods In 18 goats, two osteochondral autografts were harvested from the trochlea of the ipsilateral knee joint and inserted press-fit in a standardized articular cartilage defect in the medial femoral condyle. In half of the goats, the transplanted plugs were matched exactly to the depth of the recipient hole (bottomed plugs; $n=9$ ), whereas in the other half of the goats, a gap of $2 \mathrm{~mm}$ was left between the plugs and the recipient bottom (unbottomed plugs; $n=9$ ). After 6 weeks, all transplants were evaluated on gross morphology, subsidence, histology, and chondrocyte vitality.

Results The macroscopic morphology scored significantly higher for surface congruency in bottomed plugs as compared to unbottomed reconstructions $(P=0.04)$. However, no differences in histological subsidence scoring
\end{abstract}

N. B. Kock · G. Hannink · N. Verdonschot · P. Buma ( $₫)$ Orthopedic Research Laboratory, Department of Orthopedics, Radboud University Nijmegen Medical Center, PO Box 9101, 6500 HB Nijmegen, The Netherlands e-mail: p.buma@orthop.umcn.nl

A. van Kampen

Department of Orthopedics, Radboud University Nijmegen

Medical Center, Nijmegen, The Netherlands

J. L. C. van Susante

Department of Orthopaedics, Rijnstate Hospital,

Arnhem, The Netherlands between bottomed and unbottomed plugs were found. The transplanted articular cartilage of both bottomed and unbottomed plugs was vital. Only at the edges some matrix destaining, chondrocyte death and cluster formation was observed. At the subchondral bone level, active remodeling occurred, whereas integration at the cartilaginous surface of the osteochondral plugs failed to occur. Subchondral cysts were found in both groups.

Conclusions In this animal model, subsidence tendency was significantly lower after 'bottomed' versus 'unbottomed' osteochondral transplants on gross appearance, whereas for histological scoring no significant differences were encountered. Since the clinical outcome may be negatively influenced by subsidence, the use of 'bottomed' grafts is recommended for osteochondral transplantation in patients.

Keywords Autologous osteochondral transplantation . Osteochondral defect - Cartilage repair - Cartilage defect . Histology

\section{Introduction}

Cartilage repair is a major topic in orthopedic surgery. Even relatively small cartilage lesions frequently induce pain and disability for the patient. Without repair, small lesions may even progress to larger, more generalized arthritic lesions [21]. Commonly advocated repair techniques for these smaller lesions are microfracture, autologous chondrocyte implantation (ACI), and autologous osteochondral transplantation (AOT) [2, 28]. Compared with ACI, the advantage of AOT is that it is a one-stage procedure and mature hyaline cartilage is present in the defect site directly after transplantation. 

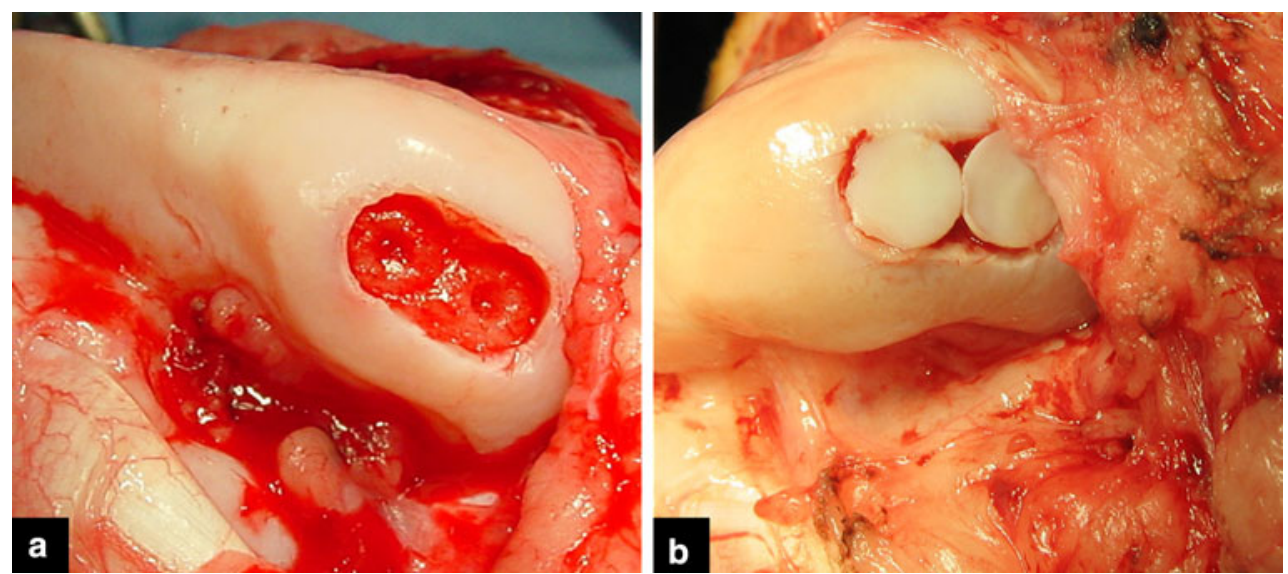

Fig. 1 a Standardized 3-mm-deep oval defect on the medial femoral condyle (length $12 \mathrm{~mm}$, width 6 mm). b Final result of a two-plug osteochondral transplantation on the medial femoral condyle

In literature both very positive reports $[7-9,13,14]$ and concerns $[1,18]$ have been presented for AOT in the knee. Concerns are related to donor site morbidity $[6,24,27]$, to survival of the transplanted cartilage $[5,11,26]$, and to the reported negative outcome in some patient series [3, 18]. Particularly mal-indications, treatment of too large defects, the use of too large plugs or co-morbidity within the knee could all negatively influence the clinical outcome of AOT $[1,18]$.

Adequate positioning, together with intrinsic stability of the transplanted plugs are likely to be important prerequisites to reach clinical success. Both are important for adequate osseous integration of the transplanted plug in the subchondral bone and for survival of the hyaline cartilage [20, 23]. In addition, osteochondral transplants should be placed flush with the joint surface, since leaving the plugs proud generates stresses at the edges leading to early damage to the graft $[19,23,29]$. Subsidence of plugs, on the other hand, leads to stresses at the rim of the host cartilage $[10,15,16]$, with similar damage there.

Earlier biomechanical studies on an AOT cadaver model, using the $\mathrm{OATS}^{\circledR}$ system, reported on relatively high forces needed to displace 'bottomed' plugs beyond flush level as compared to plugs placed with a gap between the cylinder graft and the bottom of the recipient subchondral bone defect ('unbottomed' plugs). From this biomechanical study, well-seated ('bottomed') osteochondral plugs thus seemed less susceptible for subsidence [16, 17].

The aim of this goat study was to compare bottomed versus unbottomed osteochondral transplants in vivo. It was hypothesized that bottomed plugs would indeed be superior in maintaining their flush level and by that would lead to a better gross morphology of the reconstruction and to a better survival of hyaline cartilage of both donor and host cartilage at a follow-up period of 6 weeks.

\section{Materials and methods}

Eighteen female goats were operated on the right knee joint under general anesthesia. Prior to surgery, each goat had been randomly assigned to receive two bottomed or unbottomed plugs. Centrally, in the weight-bearing area of the medial femoral condyle, a standardized oval defect (length $12 \mathrm{~mm}$, width $6 \mathrm{~mm}$ ) of $3 \mathrm{~mm}$ depth was created in an AP orientation with the use of a customized drill guide, a circular drill of $6 \mathrm{~mm}$ diameter and a small sharp osteotome (recipient site) (Fig. 1a). In accordance with clinical practice, a cylindrical osteochondral transplantation was performed to restore the articular defect using a $6 \mathrm{~mm}$ diameter osteochondral autograft transfer system $\left(\right.$ OATS $^{\circledR}$; Arthrex, St. Anthonis, The Netherlands).

Two donor osteochondral plugs were harvested from the lateral trochlea of the goat knee, which is in accordance with the situation in patients [25]. Care was taken to harvest plugs as much perpendicular to the articular surface as possible without penetrating the lateral wall of the trochlear groove. The harvested donor plugs were adjusted to an exact length of $8 \mathrm{~mm}$, measured with a precision slide calliper, by removal of some deep trabecular bone by a surgical bone nibbling plier.

The recipient site was restored using the two available donor plugs from the trochlea. Depending on the assigned treatment, a recipient hole with an 8 or $10 \mathrm{~mm}$ depth was created in the femoral condyle defect for a bottomed or unbottomed situation, respectively. The precise depth was verified with a vernier calliper. The bottom of the recipient hole was softly tampered, with the provided steel rod, to flatten it in order to ensure an exact matching depth and direct contact of the transplanted plug on the bottom of the recipient hole in case of a bottomed transplantation. Subsequently, the available donor osteochondral plug was gently tampered into place until flush level with the 
adjacent articular cartilage was obtained. After the first plug was in place, the entire procedure was repeated for the second transplant (Fig. 1b). As a result in the bottomed situation, plugs were seated exactly on the flattened bottom, and in the unbottomed situation, the plugs were floating $2 \mathrm{~mm}$ above the flattened bottom.

The trochlear donor site defects were either left empty in six goats or were filled with impacted remainders of the available subchondral bone derived from preparing the recipient holes, leaving small, but shallow defects (12 goats). In six of these 12 goats, the remaining shallow defects were completely filled up to a flush level with a commercially available hemostatic collagen type I sponge (Spongostan $^{\mathrm{TM}}$; Ferrosan A/S, Soeborg, Denmark). It was hypothesized that partly restoring the donor defect with the available impacted subchondral bone would lead to a better healing of these defects as compared to empty defects. In addition, filling the remaining defect with a collagen type I sponge would then possibly further enhance the healing process of the donor defect.

Directly after surgery, the goats were placed in a hammock for 7 days. The first 3 days the goats received standard injections of flunixine $(1 \mathrm{mg} / \mathrm{kg}) \quad$ Finadyne $^{\circledR}$; Schering-Plough Animal Health, Oss, The Netherlands) and buprenorphine $(0.018 \mathrm{ml} / \mathrm{kg}) \quad\left(\right.$ Temgesic $^{\circledR} ; \quad$ MSD Animal Health, Oss, The Netherlands) as analgesic. Antibiotic prophylaxis consisted of ampicillin subcutaneously administered for 5 days postoperatively $(7.5 \mathrm{ml} /$ day $)$ (Albupen ${ }^{\circledR}$; Intervet, Boxmeer, The Netherlands). After 7 days, the goats were transported in the hammock to an outdoor farm where they were allowed to move freely and unrestricted.

All goats received one injection of three different fluorochromes. After 2 weeks, tetracycline $(25 \mathrm{mg} / \mathrm{kg})$ was administered, after 4 weeks calcein green $(25 \mathrm{mg} / \mathrm{kg})$ and finally after 6 weeks, 2 days before killing, alizarin red $(30 \mathrm{mg} / \mathrm{kg})$. After 6 weeks, the goats were killed with an overdose of pentobarbital (Nembutal ${ }^{\circledR}$, CEVA Santé Animale, Maassluis, The Netherlands) and the knee joint was completely dissected from femur en tibia. All investigations were conducted in conformity with ethical principles of research and all protocols were approved by the institutional Animal Ethics Committee (RU-DEC2007-106).

\section{Macroscopic scoring}

Directly after harvesting, the knee joint was opened and photographs of the recipient and donor sites were taken. The photographs of the reconstructions were evaluated by three blinded observers (NK, GH, and $\mathrm{PB}$ ) and scored for gross morphological appearance of the surface congruency of individual plugs (Table 1). Subsidence, protrusion, tilting, sclerosis, and fibrous overgrowth were considered to
Table 1 Macroscopic scoring system

\begin{tabular}{ll}
\hline Characteristics & Score \\
\hline Clinical acceptable or flush—virtually no negative signs & 2 \\
Clinical suboptimal—-minor negative signs & 1 \\
Clinical failure—obvious negative signs & 0 \\
\hline
\end{tabular}

Subsidence, protrusion, tilting, sclerosis, and fibrous overgrowth were considered as negative signs

be negative signs. The separate scores of each of both transplanted plugs were added, resulting in a maximum score of 4 per goat.

\section{Microscopic preparation}

The operated condyle was dissected with a diamondcoated and water-cooled sawing blade (blade thickness $300 \mu \mathrm{m})$ exactly in two halves in the AP direction through the center of the two plugs and photographs were taken again. Thereafter, two slices were made from each section plane of both halves of the defect and processed for histology.

The two slices were used for vitality testing with Cell Tracker Green CMFDA (5-chloromethylfluorescein diacetate; Molecular Probes, Invitrogen Ltd, UK) and propidium iodide (Molecular Probes, Invitrogen Ltd., UK). Directly following coloring, the specimens were photographed through a fluorescence photomicroscope (Zeiss Axioplan 2; Carl Zeiss BV, Sliedrecht, The Netherlands) and frozen afterward. In a later stage, they were defrosted and vital cells were colored by NADH-diaphorase (Sigma-Aldrich Chemie BV, Zwijndrecht, The Netherlands) with nitrobluetetrazolium (NBT; Sigma-Aldrich Chemie BV, Zwijndrecht, The Netherlands). After taking photographs, these slices were further processed for routine histology as described below.

All specimens were fixated in a $4 \%$ buffered formalin solution ( $\mathrm{pH}$ 7.4) for at least 1 day. The specimens were embedded in polymethylmethacrylate and sectioned (7- $\mu$ m-thick sections) with a microtome (Leica RM 2155, Leica Microsystems Nederland BV, Rijswijk, The Netherlands), and stained with Hematoxylin and Eosin, Alcian Blue and Safranin O. Serial sections of the trochlear donor defect were prepared in the transverse direction.

\section{Histological scoring}

The reconstructions were graded for graft level with surrounding cartilage, graft cartilage thickness, cartilage integration, degenerative changes at cartilage edges, changes in tidemarks at cartilage edges, integration of adjacent subchondral bone, and subchondral cavity formation (Table 2). This scoring system was adapted from 
Table 2 Histological scoring system

\begin{tabular}{|c|c|}
\hline Characteristics & Scor \\
\hline \multicolumn{2}{|l|}{ Graft level with surrounding cartilage } \\
\hline Level & 4 \\
\hline$<50 \%$ of graft cartilage thickness-below & 3 \\
\hline$<50 \%$ of graft cartilage thickness-raised & 2 \\
\hline$>50 \%$ of graft cartilage thickness-below & 1 \\
\hline$>50 \%$ of graft cartilage thickness-raised & 0 \\
\hline \multicolumn{2}{|l|}{ Graft cartilage thickness } \\
\hline $75-100 \%$ of adjacent cartilage & 2 \\
\hline $50-75 \%$ & 1 \\
\hline$<50 \%$ & 0 \\
\hline \multicolumn{2}{|l|}{ Cartilage integration } \\
\hline Bonding through cartilage like tissue & 3 \\
\hline Fissure fully filled with fibrous tissue & 2 \\
\hline Fissure partially filled with fibrous tissue & 1 \\
\hline Empty fissure & 0 \\
\hline \multicolumn{2}{|l|}{ Degenerative changes at cartilage edges } \\
\hline Normal cellularity, no clusters, normal staining & 3 \\
\hline Mild hypocellularity, some clusters, moderate staining & 2 \\
\hline Moderate hypocellularity, slight staining & 1 \\
\hline Severe hypocellularity, poor or no staining & 0 \\
\hline \multicolumn{2}{|l|}{ Changes in tidemarks at cartilage edges } \\
\hline Both normal & 2 \\
\hline One damaged or abnormal & 1 \\
\hline Both damaged or abnormal & 0 \\
\hline \multicolumn{2}{|l|}{ Integration of adjacent subchondral bone } \\
\hline Fully osseous integration & 4 \\
\hline Fully integrated with partial fibrous tissue & 3 \\
\hline Fully integrated only fibrous tissue & 2 \\
\hline Partially integrated & 1 \\
\hline No integration & 0 \\
\hline \multicolumn{2}{|l|}{ Subchondral cavity formation } \\
\hline No cavities & 3 \\
\hline Small cavities & 1 \\
\hline Large cavity & 0 \\
\hline Total maximum score per location & 21 \\
\hline
\end{tabular}

In each reconstruction, 3 locations were evaluated, the anterior hostplug contact area (A), the central plug-plug contact area (B), and the posterior plug-host contact area (C). The scores for each location were summed to obtain a total score for each reconstruction

similar scales for osteochondral cartilage repair published by other researchers $[4,22]$. The same three blinded observers (NK, GH, and $\mathrm{PB}$ ) scored two specimens from the center of the repaired defect independent of each other. In each reconstruction, 3 locations were evaluated, the anterior host-plug contact area (A), the central plug-plug contact area (B), and the posterior plug-host contact area (C). The scores for each location were summed to obtain a total score for each reconstruction.
Statistical analysis

Datasets from gross morphological scoring and histological grading were evaluated nonparametrically, as normal distribution could not be assumed for all parameters. Unpaired comparisons between bottomed and unbottomed plugs were made using the Mann-Whitney $U$ test (Wilcoxon rank sum test). A $P$ value $<0.05$ was regarded as statistically significant.

\section{Results}

Macroscopic scoring

The gross morphological scoring showed a significantly higher score for surface congruency in bottomed plugs as compared to unbottomed reconstructions $(P=0.04)$ (Table 3).

\section{Microscopic scoring}

No differences between local and total histological grading scores for bottomed and unbottomed plugs were found (Table 4).

Histology of the plugs

Both the NADH-diaphorase staining and the life dead assay showed a similar distribution of vital and necrotic cells (Fig. 2). Most chondrocytes of the host cartilage and transplanted plugs were vital (Fig. 2a, b, c). Necrotic

Table 3 Macroscopic scores

\begin{tabular}{llll}
\hline & Bottomed $(n=9)$ & Unbottomed $(n=9)$ & $P$ value \\
\hline Anterior plug & $1.5 \pm 0.4$ & $0.8 \pm 0.7$ & 0.03 \\
Posterior plug & $1.2 \pm 0.7$ & $0.7 \pm 0.8$ & n.s. \\
Total & $2.7 \pm 0.8$ & $1.5 \pm 0.4$ & 0.04 \\
\hline
\end{tabular}

Values are mean $\pm \mathrm{SD}$

n.s. $=P \geq 0.05$

Table 4 Microscopic scores

\begin{tabular}{lccl}
\hline & Bottomed $(n=9)$ & Unbottomed $(n=9)$ & $P$ value \\
\hline A & $11.1 \pm 3.6$ & $12.3 \pm 3.0$ & n.s. \\
B & $8.8 \pm 3.0$ & $9.7 \pm 3.3$ & n.s. \\
C & $12.3 \pm 2.5$ & $11.3 \pm 3.7$ & n.s. \\
Total & $32.0 \pm 6.0$ & $32.1 \pm 8.5$ & n.s. \\
\hline
\end{tabular}

Values are mean \pm SD. (A) anterior host-plug contact area, (B) the central plug-plug contact area, and (C) the posterior plug-host contact area

n.s. $=P \geq 0.05$ 
Fig. 2 Histology of sections stained with NADH-diaphorase with NBT (nitrobluetetrazolium) for vitality $(\mathbf{a}, \mathbf{b}, \mathbf{c})$ and section $(\mathbf{d})$ in which living cells are stained with Cell Tracker Green. Notice difference in thickness between host $(H)$ and plug $(P)$ cartilage. In $\mathbf{b}$ the lower square box is a magnification of the upper square box. a, b bottomed reconstructions, $\mathbf{c}$, d unbottomed reconstructions
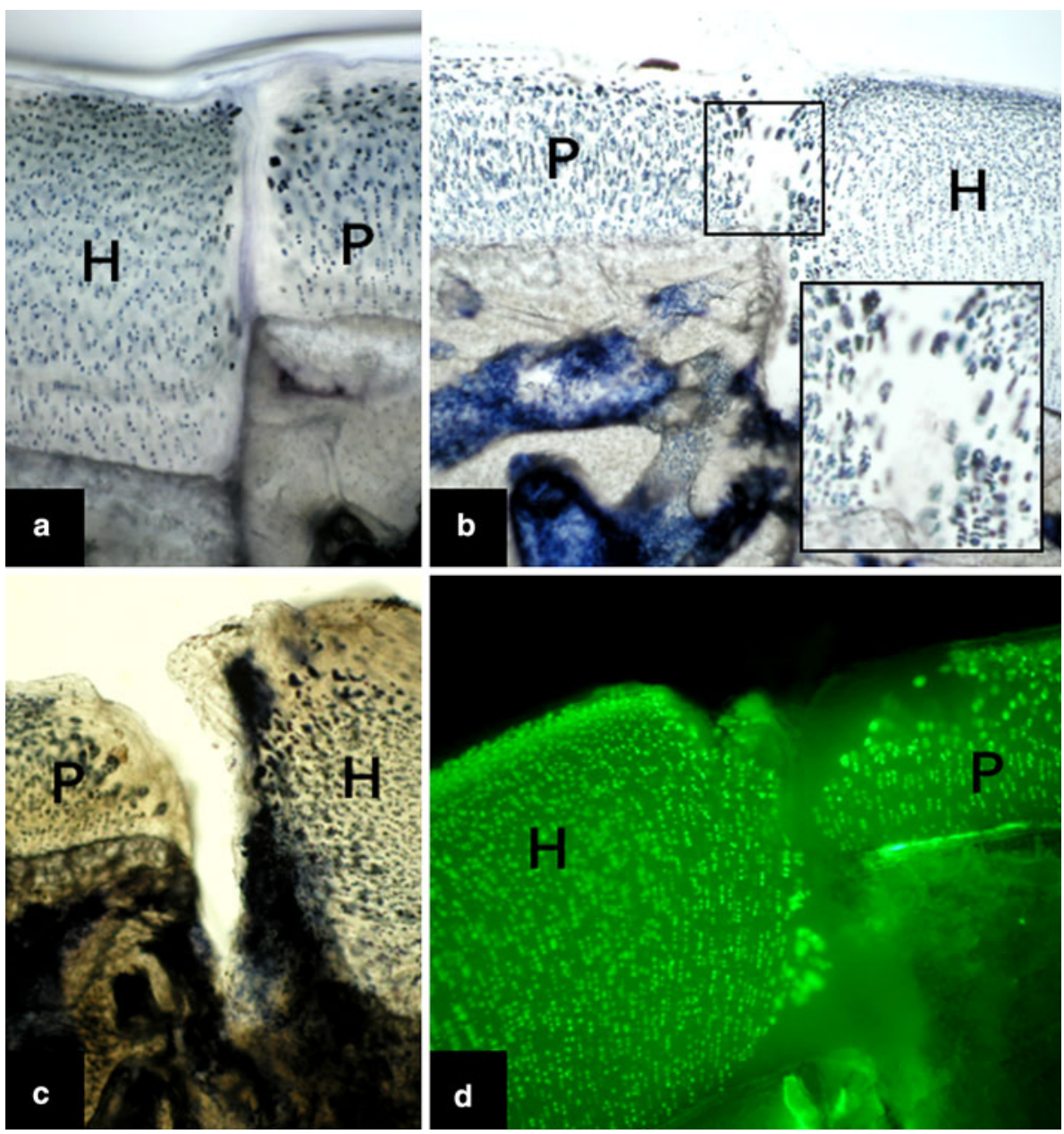

chondrocytes were present in equal low numbers in both host and plug articular cartilage. Only at the edges toward the interface between plugs, there was a thin acellular zone of cartilage (Fig. 2a, d). Bordering this acellular layer, clustered chondrocytes were present in almost all plugs and bordering host cartilage (Fig. 2b). Generally, plugs were in close contact with each other (Fig. 2a, b, d). Occasionally, larger gaps were also present (Figs. 2c, 3b). The cartilage interface between plugs was in most cases very thin and plugs seemed to be press-fit (Fig. 3a). No integration of cartilage in between plugs or between plugs and host cartilage was found.

\section{Integrity of the tidemark}

The tidemarks were generally intact (Fig. 4a). Particularly, if the subchondral bone was revascularized, small capillaries of the newly formed fibrous subchondral tissue were penetrating the tidemark, and by that, the integrity of the tidemark was reduced (Fig. 4b). Integration of neighboring tidemarks between neighboring plugs was never observed.

\section{Subchondral bone remodeling}

The central part of the subchondral bone of the transplanted plugs was still mainly avascular and necrotic with empty osteocyte lacunae and necrotic medullary tissue. From the deeper parts of the defect and from the interfaces with the host bone, a process of creeping substitution of the necrotic bone was present. This process was characterized by abundant osteoclastic resorption sites of the transplanted bone (Fig. 3c), new bone formation on the remnants of the bone of the plugs and bone remodeling. Most of the new bone was directly formed as woven bone (Fig. 3d); however, irrespective of the treatment group, in various locations in the subchondral areas, small areas of enchondral bone formation were present.

\section{Donor site}

Irrespective to the treatment modality, all donor sites showed rather similar histological appearances. In the defects, mainly fibrous tissue or fat marrow was present (Fig. 5a). Only at the edges of the defects in some cases, 
Fig. 3 Routine histology staining of thin sections with Safranin $\mathrm{O}(\mathbf{a}, \mathbf{b})$ and

Haematoxylin and eosin $(\mathbf{c}, \mathbf{d})$. a, c bottomed plugs,

b, $\mathbf{d}$ unbottomed plugs. a Notice cartilage-like tissue formation in the gap between the two inserted plugs $(P)$. In $\mathbf{b}$ a larger nonfilled gap is present between host $(H)$ and plug $(P)$ cartilage. c Resorptive phase (arrows point at osteoclasts) in subchondral bone remodeling. d New bone formation in subchondral bone of transplanted plug
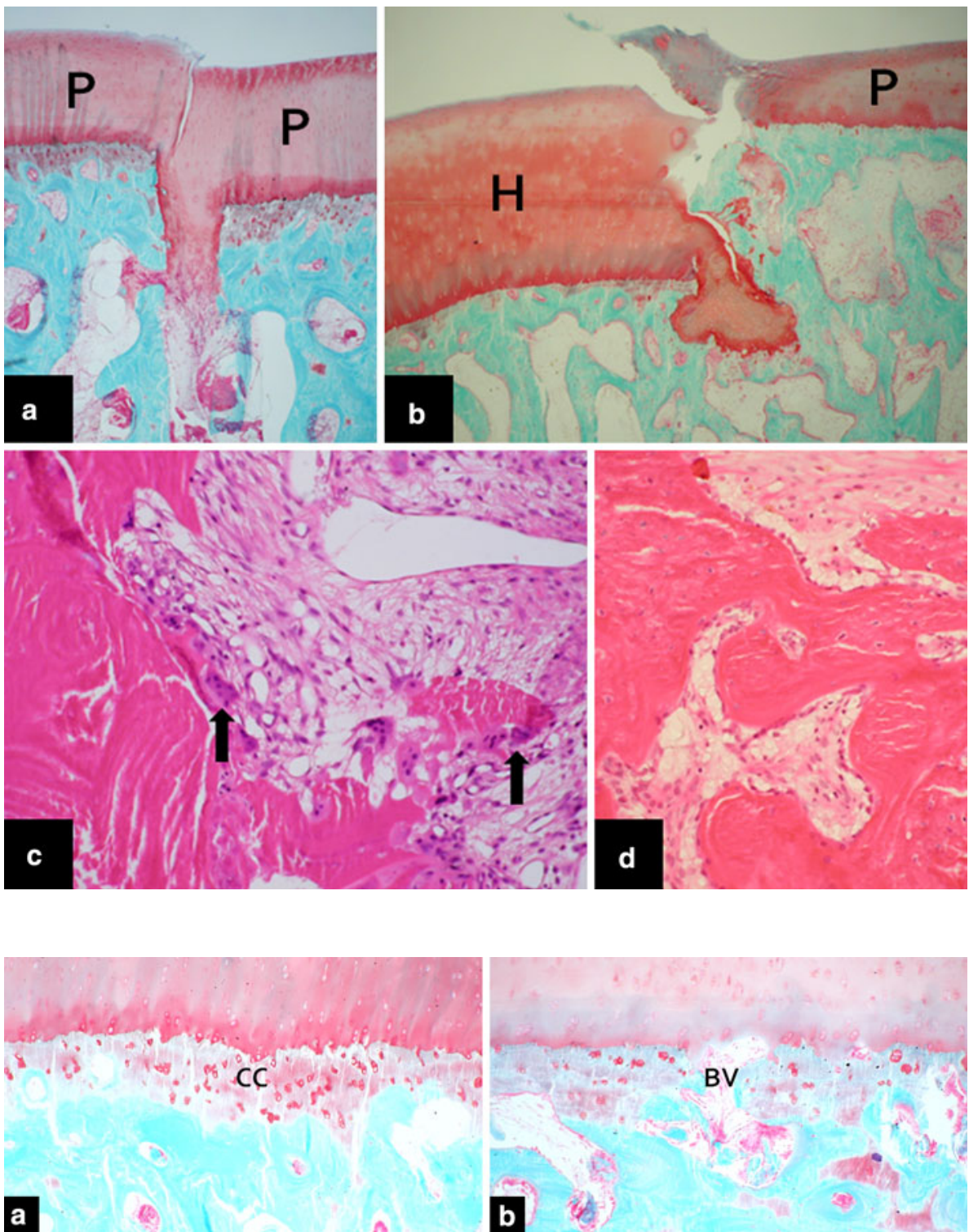

Fig. 4 Subchondral bone of host (a), and of unbottomed plug. $C C$ is calcified cartilage. $B V$ is a blood vessel penetrating to the tidemark

\section{Discussion}

The most important finding of the present study was that chondrocyte vitality was maintained after osteochondral transplantation. On gross appearance, bottomed plugs seemed to reveal lesser subsidence tendency than unbottomed plugs; however, on histological evaluation, no significant differences could be detected between groups. In addition, the repair tendency of the donor defects was not improved by the two different filling techniques evaluated in this animal model.

Gross morphological scoring showed that the bottomed plugs performed superior in maintaining flush level with the surrounding subchondral bone. The fact that on histological scoring bottomed and unbottomed plugs failed to reveal a significant difference may be induced by the (Fig. 5d). 

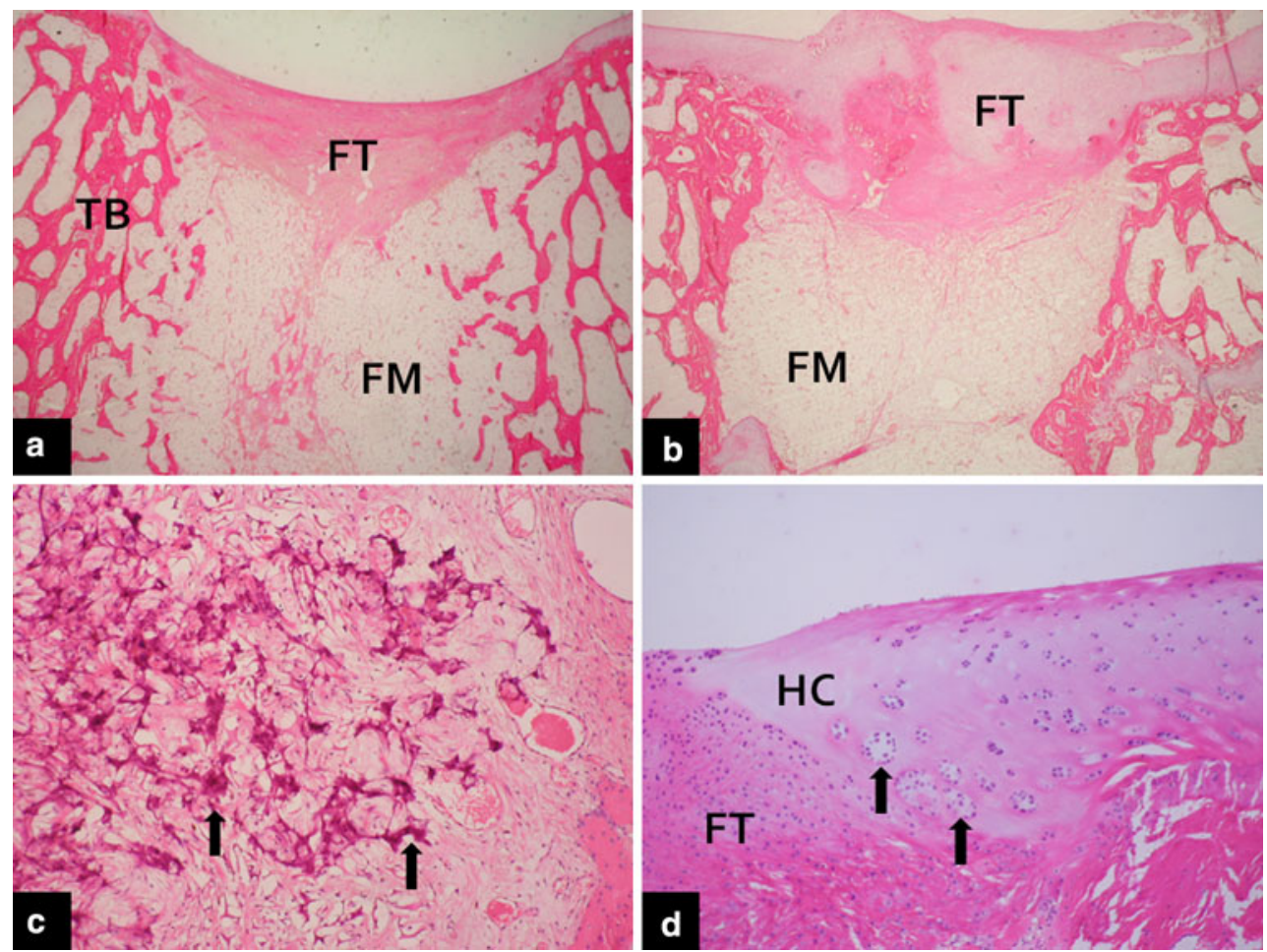

Fig. 5 a, b Haematoxylin and eosin-stained sections showing representative micrographs of donor site. a Empty defect. b and c defect filled with bone graft with spongostan. c Remnants of the

scoring method itself. The histological scoring was performed in the mid-sagittal plane only, whereas for macroscopic evaluation, the entire contour of the transplantation was judged and not just the appearance of the mid-sagittal plane (see also Fig. 6 for further explanation). Irrespective the fact that histological scoring was performed on the midsagittal plane only, it has to be recognized that no major differences were encountered between bottomed and unbottomed plugs. Clearly the extent of subsidence was relatively low in this animal model, which may be related to the compact subchondral bone structure of goats. Irrespective of the absence of a significant difference between the two groups, the evaluated different aspects of the histological score are still important parameters for the long-term success of the AOT technique. The most important long-term success aspect of the AOT technique above the ACI techniques or microfracture is the instantaneous restoration of the defect site with mature healthy hyaline cartilage, which was indeed confirmed in our study by an excellent chondrocyte vitality after transplantation.

Chondrocyte survival also appears to be dependent on the harvesting procedure of the osteochondral graft [11], where sharper cutting devices reduce the thickness of the layer of dead chondrocytes [12]. Moreover, harvesting by hand is superior above power trephine harvesting [5]. In collagen type I sponge (arrows). d Edge of host cartilage $(H C)$ with clustered chondrocytes (arrows)

this study, only small margins of the plugs were acellular, indicating that indeed also limited chondrocyte death took place during the harvest. Besides the harvesting procedure, tampering the plugs into the bone might also induce chondrocyte death at the surface of the plugs. The fact that in both groups the surface layer was populated with vital cells indicated that the tempering probably did not induce a necrosis of the superficial chondrocytes. This indicates that the clinically used forces to insert plugs are most likely within the margin to induce cartilage damage, especially since goat cartilage is thinner and thereby more prone to damage, and higher tempering force is needed in the more compact goat bone, compared with human bone.

The potential for donor site morbidity is still a major drawback of the AOT technique and is held responsible for inferior results in some studies. For that reason, we evaluated some simple attempts to enhance the healing potential of these defects. However, filling the donor site defects with impacted cancellous bone, with or without a collagen type I layer, did not induce any new subchondral bone restoration as compared to empty defects. Although in the deeper parts of the defects some new bone was formed, there was no relation with the graft material.

This animal model on osteochondral transplantation has some clear limitations. Goats and sheep are widely 


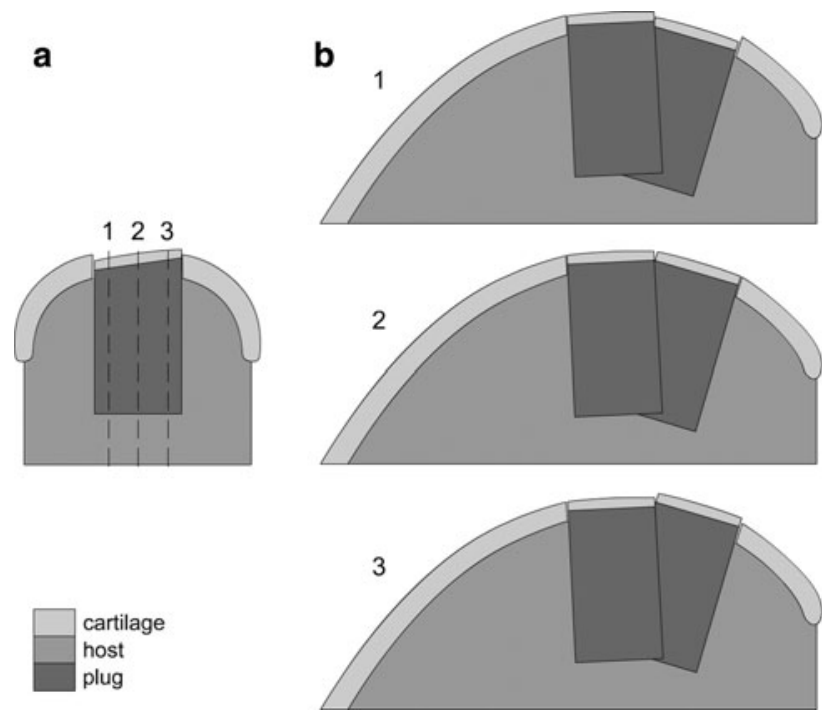

Fig. 6 Schematics for illustrating the possible discrepancy in judging the (flush) level of a whole graft through microscopic sections of the specimen. a Represents a sagittal view on the condyle. b Represents an A-P view of on the condyle. The dotted lines indicate the outer boundaries of the two thick sections, which were made. Notice the less than optimal perpendicularity of the plug's cartilage surface in respect to its subchondral bone in this schematic representation. c Represents the lateral view of the theoretical sections made at the dotted lines in b. 1 Notice the subsidence below flush level of the posterior (right) plug. 2 Notice the flush level of the posterior (right) plug. 3 Notice the protrusion above flush level of the posterior (right) plug

used large preclinical relevant models for human articular cartilage diseases. However, the results and recommendations from this study for patients should be carefully interpreted within the limitations of the model. Bone of healthy animals is of good quality and because of high loads more compact than in humans, which may have resulted in a more tightly press-fit placement of the plugs and thus a relative resistance to subsidence tendency. This phenomenon may have played a role in the encountered absence of a significant difference between 'bottomed' and 'unbottomed' groups on histological scoring.

Furthermore, it has to be recognized that in this study an osteochondral transplantation using the $\mathrm{OATS}^{\circledR}$ system was evaluated, which system on theoretical grounds may offer less intrinsic stability to the transplanted plugs than the alternatively available Mosaicplasty ${ }^{\mathrm{TM}}$ system. In contrast to the OATS ${ }^{\circledR}$ system, in the Mosaicplasty ${ }^{\mathrm{TM}}$ system, primary stability of the transplants is not only dependent on the standard shear forces between plug and host bone, but also on the conically shaped bottom part of the defect created by means of a dilator. The recommendation to bottom osteochondral plugs may thus mainly apply to the currently evaluated OATS ${ }^{\circledR}$ system.

\section{Conclusions}

Autologous osteochondral transplantation can indeed restore a joint defect with vital hyaline articular cartilage. Subsidence of the transplanted plugs may be detrimental for the eventual clinical outcome and should be avoided. In this animal model, using the OATS ${ }^{\circledR}$ system, macroscopic scoring revealed less subsidence tendency when the transplanted plugs were bottomed. In spite of the fact that the encountered benefit of bottoming was only limited in this animal model, bottoming is still recommended for clinical practice, especially when the OATS ${ }^{\circledR}$ system is used. Larger comparative clinical trials will be necessary to truly elucidate the potential clinical benefit of bottoming.

Acknowledgments The authors thank Léon Driessen for histotechnical assistance. This study was unconditionally supported financially by the Dutch Arthritis Association (Reumafonds) as well as the Dutch Anna Foundation (Anna Fonds).

Conflict of interest All authors declare that there are no conflicts of interest.

Open Access This article is distributed under the terms of the Creative Commons Attribution Noncommercial License which permits any noncommercial use, distribution, and reproduction in any medium, provided the original author(s) and source are credited.

\section{References}

1. Alford JW, Cole BJ (2005) Cartilage restoration, part 2: techniques, outcomes, and future directions. Am J Sports Med 33:443-460

2. Bekkers JE, Inklaar M, Saris DB (2009) Treatment selection in articular cartilage lesions of the knee: a systematic review. Am J Sports Med 37(Suppl 1):148-155

3. Bentley G, Biant LC, Carrington RW, Akmal M, Goldberg A, Williams AM, Skinner JA, Pringle J (2003) A prospective, randomised comparison of autologous chondrocyte implantation versus mosaicplasty for osteochondral defects in the knee. J Bone Joint Surg Br 85:223-230

4. Buma P, Pieper JS, van Tienen T, van Susante JL, van der Kraan PM, Veerkamp JH, van den Berg WB, Veth RP, van Kuppevelt TH (2003) Cross-linked type I and type II collagenous matrices for the repair of full-thickness articular cartilage defects-a study in rabbits. Biomaterials 24:3255-3263

5. Evans PJ, Miniaci A, Hurtig MB (2004) Manual punch versus power harvesting of osteochondral grafts. Arthroscopy 20:306-310

6. Feczko P, Hangody L, Varga J, Bartha L, Dioszegi Z, Bodo G, Kendik Z, Modis L (2003) Experimental results of donor site filling for autologous osteochondral mosaicplasty. Arthroscopy 19:755-761

7. Hangody L, Dobos J, Balo E, Panics G, Hangody LR, Berkes I (2010) Clinical experiences with autologous osteochondral mosaicplasty in an athletic population: a 17-year prospective multicenter study. Am J Sports Med 38:1125-1133

8. Hangody L, Fules P (2003) Autologous osteochondral mosaicplasty for the treatment of full-thickness defects of weight- 
bearing joints: ten years of experimental and clinical experience. J Bone Joint Surg Am 85(Suppl 2):25-32

9. Horas U, Pelinkovic D, Herr G, Aigner T, Schnettler R (2003) Autologous chondrocyte implantation and osteochondral cylinder transplantation in cartilage repair of the knee joint. A prospective, comparative trial. J Bone Joint Surg Am 85:185-192

10. Huang FS, Simonian PT, Norman AG, Clark JM (2004) Effects of small incongruities in a sheep model of osteochondral autografting. Am J Sports Med 32:1842-1848

11. Huntley JS, Bush PG, McBirnie JM, Simpson AH, Hall AC (2005) Chondrocyte death associated with human femoral osteochondral harvest as performed for mosaicplasty. J Bone Joint Surg Am 87:351-360

12. Huntley JS, McBirnie JM, Simpson AH, Hall AC (2005) Cuttingedge design to improve cell viability in osteochondral grafts. Osteoarthritis Cartilage 13:665-671

13. Jakob RP, Franz T, Gautier E, Mainil-Varlet P (2002) Autologous osteochondral grafting in the knee: indication, results, and reflections. Clin Orthop Relat Res 401:170-184

14. Karataglis D, Green MA, Learmonth DJ (2006) Autologous osteochondral transplantation for the treatment of chondral defects of the knee. Knee 13:32-35

15. Kock N, van Susante J, Wymenga A, Buma P (2004) Histological evaluation of a mosaicplasty of the femoral condyle-retrieval specimens obtained after total knee arthroplasty-a case report. Acta Orthop Scand 75:505-508

16. Kock NB, Smolders JM, van Susante JL, Buma P, van Kampen A, Verdonschot N (2008) A cadaveric analysis of contact stress restoration after osteochondral transplantation of a cylindrical cartilage defect. Knee Surg Sports Traumatol Arthrosc $16: 461-468$

17. Kock NB, van Susante JL, Buma P, van Kampen A, Verdonschot N (2006) Press-fit stability of an osteochondral autograft: influence of different plug length and perfect depth alignment. Acta Orthop 77:422-428

18. Kock NB, van Tankeren E, Oyen WJ, Wymenga AB, van Susante JL (2010) Bone scintigraphy after osteochondral autograft transplantation in the knee: 13 patients followed for 4 years. Acta Orthop 81:206-210

19. Koh JL, Wirsing K, Lautenschlager E, Zhang LO (2004) The effect of graft height mismatch on contact pressure following osteochondral grafting: a biomechanical study. Am J Sports Med $32: 317-320$

20. Makino T, Fujioka H, Yoshiya S, Terukina M, Matsui N, Kurosaka M (2002) The effect of the small and unstable autologous osteochondral graft on repairing the full-thickness large articular cartilage defect in a rabbit model. Kobe J Med Sci 48:97-104

21. Maletius W, Messner K (1996) The effect of partial meniscectomy on the long-term prognosis of knees with localized, severe chondral damage. A twelve- to fifteen-year followup. Am J Sports Med 24:258-262

22. Niederauer GG, Lee DR, Sankaran S (2006) Bone grafting in arthroscopy and sports medicine. Sports Med Arthrosc 14:163-168

23. Pearce SG, Hurtig MB, Clarnette R, Kalra M, Cowan B, Miniaci A (2001) An investigation of 2 techniques for optimizing joint surface congruency using multiple cylindrical osteochondral autografts. Arthroscopy 17:50-55

24. Sgaglione NA, Miniaci A, Gillogly SD, Carter TR (2002) Update on advanced surgical techniques in the treatment of traumatic focal articular cartilage lesions in the knee. Arthroscopy 18:9-32

25. Smolders JM, Kock NB, Koeter S, van Susante JL (2010) Osteochondral autograft transplantation for osteochondritis dissecans of the knee. Preliminary results of a prospective case series. Acta Orthop Belg 76:208-218

26. Tibesku CO, Szuwart T, Kleffner TO, Schlegel PM, Jahn UR, Van Aken H, Fuchs S (2004) Hyaline cartilage degenerates after autologous osteochondral transplantation. J Orthop Res 22:1210-1214

27. van Susante JL, Wymenga AB, Buma P (2003) Potential healing benefit of an osteoperiosteal bone plug from the proximal tibia on a mosaicplasty donor-site defect in the knee. An experimental study in the goat. Arch Orthop Trauma Surg 123:466-470

28. Vasiliadis HS, Wasiak J, Salanti G (2010) Autologous chondrocyte implantation for the treatment of cartilage lesions of the knee: a systematic review of randomized studies. Knee Surg Sports Traumatol Arthrosc 18:1645-1655

29. Wu JZ, Herzog W, Hasler EM (2002) Inadequate placement of osteochondral plugs may induce abnormal stress-strain distributions in articular cartilage-finite element simulations. Med Eng Phys 24:85-97 